\section{Tradução e adaptação transcultural do domínio Fadiga do Patient-Reported-Outcomes Measurement Information System (PROMIS) para a língua portuguesa}

\author{
Portuguese-language translation and cross-cultural \\ adaptation of the Fatigue domain of Patient- \\ Reported-Outcomes Measurement Information \\ System (PROMIS)
}

Traducción e interculturalidad en el ámbito de la fatiga con la adaptación del Patient-ReportedOutcomes Measurement Information System (PROMIS) en lengua portuguesa

\begin{abstract}
The items bank of the Fatigue domain is part of an American system developed for evaluation of results reported by patients, called PatientReported-Outcomes Measurement Information System (PROMIS). This study aimed to translate and cross-culturally adapt this item bank for the Brazilian population, as a promising new tool for evaluating health-related quality of life. The items in this bank were translated using rigorous translation and back-translation protocols. The translated version was pre-tested in twenty Brazilians with a brief cognitive and retrospective interview in order to test the items' conceptual, cultural, and semantic equivalences. In the translation and back-translation process, only three of the 82 items had to be reworded due to the culturally inadequate content. In the pretest, only four items needed to be reworded, but without conceptual and semantic alterations. The results showed that the translated version of this item bank is conceptually, culturally, and semantically equivalent to the original version.
\end{abstract}

Fatigue; Quality of Life; Translating
Flávio Sérgio Marques Alves 1 Rogério de Melo Costa Pinto 1 Tânia Maria Silva Mendonça 1 Carlos Henrique Martins da Silva ${ }^{1}$

\title{
Resumo
}

O banco de itens do domínio Fadiga faz parte de um sistema americano desenvolvido para avaliação de resultados relatados pelos pacientes denominado Patient-Reported-Outcomes Measurement Information System (PROMIS). Este estudo teve como objetivo traduzir e adaptar transculturalmente esse banco de itens para a população brasileira por ser uma nova promessa de avaliação da qualidade de vida relacionada à saúde. Os itens deste banco foram traduzidos, utilizando protocolos rigorosos de tradução e retrotradução. A versão traduzida foi pré-testada por vinte brasileiros que responderam a uma breve entrevista cognitiva e retrospectiva a fim de testar as equivalências conceitual, cultural e semântica dos itens. No processo de tradução e retrotradução, apenas três dos 82 itens tiveram de ser reescritos devido ao conteúdo culturalmente inadequado. No pré-teste, apenas quatro itens necessitaram ser reescritos, mas sem alteração conceitual e semântica. Os resultados demonstram que a versão traduzida desse banco de itens é conceitual, cultural e semanticamente equivalente à sua versão original.

Fadiga; Qualidade de Vida; Tradução 


\section{Introdução}

Avaliações de intervenções realizadas em pacientes com doenças crônicas por meio de seus próprios relatos (Patient-Reported Outcomes - PROs) são de grande valia por serem responsáveis por alterações na qualidade de vida desses pacientes 1 .

Uma nova metodologia visando melhorar a avaliação dos PROs, o Patient-Reported-Outcome Measurement Information System (PROMIS) foi desenvolvida pelo National Institute of Health, norte-americano (PROMIS Cooperative Group. Unpublished manual for the Patient Reported Outcomes Measurement Information System PROMIS. http://www.nihpromis.org, acessado em 11/Mai/2013). Esse sistema teve como desafio o desenvolvimento de um grande banco de itens retirados de instrumentos clássicos e concentrados em domínios de avaliação física e psicossocial 2 , com a vantagem de o paciente responder a um número mínimo de itens por meio dos modelos da Teoria de Resposta ao Item (TRI) e do Teste Adaptativo Computadorizado (CAT), sendo aplicado com a utilização do software Assessment Center (PROMIS Network. http:/ / www. nihpromis.org/software/assessmentcenter?As pxAutoDetectCookieSupport=1, Silver Spring, Estados Unidos) disponibilizado em computador 2, além de resultar em respostas e informações mais precisas.

Um dos bancos de itens do PROMIS é o sintoma Fadiga 3, sendo este de difícil definição e etiologia multifatorial. É um sintoma subjetivo de sensação desagradável de cansaço que dificilmente é aliviado com medidas usuais para restauração de energia, e que promove impacto negativo nos aspectos físicos, psíquicos e emocionais das pessoas, comprometendo sua qualidade de vida relacionada à saúde. A duração e intensidade desse sintoma são variáveis entre as pessoas e reduz, em diferentes graus, sua habilidade para executar as atividades de vida diária, além de reduzir a capacidade profissional e de socialização ${ }^{3}$. O objetivo desse estudo foi traduzir e adaptar transculturalmente, para a língua portuguesa, o banco de itens Fadiga do PROMIS, uma vez que sua versão original está no inglês americano e, portanto, para ser utilizado no Brasil é necessário realizar esse processo.

\section{Métodos}

Estudo de tradução e adaptação transcultural de acordo com a metodologia ${ }^{4}$ proposta pelos administradores do PROMIS com as etapas representadas na Figura 1.

\section{Instrumento}

Banco de itens composto por 82 itens divididos em duas dimensões: 47 itens para avaliação do impacto da fadiga (em atividades físicas, mentais e sociais) e 35 que avaliam a experiência com a fadiga quanto à sua intensidade, frequência e duração.

\section{Tradução e adaptação transcultural}

Por orientação dos administradores do PROMIS, durante o processo de tradução foi mantida a universalização da tradução a fim de que ela pudesse ser utilizada nos países que falam a língua portuguesa.

O processo de tradução de adaptação transcultural 4 do domínio Fadiga do PROMIS envolveu as seguintes etapas:

a) Tradução inicial: realizada por dois tradutores profissionais em linguística;

b) Reconciliação: realizada por um tradutor especialista em linguística que teve como objetivo resolver discrepâncias relacionadas à definição dos itens;

c) Retrotradução: a versão reconciliada foi traduzida para a língua original, o inglês por um tradutor profissional que não teve contato com a versão original;

d) Comparação entre a retrotradução e a escala original: a versão retrotraduzida foi enviada aos administradores do PROMIS a fim de identificar traduções inapropriadas e ambíguas e avaliar a equivalência conceitual e semântica em relação à versão original;

e) Revisores independentes: os itens retrotraduzidos foram encaminhados a quatro revisores independentes, sendo três brasileiros da Universidade Federal de Uberlândia (UFU) e um português, bilíngues, profissionais em linguística, não envolvidos nos estágios anteriores, para análise e possíveis colaborações;

f) Processo final de revisão: após o término da revisão, o relatório foi reencaminhado aos administradores do PROMIS para aprovação da versão traduzida;

g) Pré-teste: o conceito de fadiga foi apresentado aos participantes conforme orientações das definições dos itens propostas pelos administradores do PROMIS. A versão pré-final dos itens foi aplicada a vinte respondentes com idade entre 20 e 60 anos, recrutados no Hospital das Clínicas da UFU. Cada item foi respondido por cinco pessoas que responderam também a entrevistas cognitivas e retrospectivas relacionadas às dificuldades de entendimento dos itens 5,6. Dos respondentes, 14 (70\%) eram mulheres; $5 \%$, do total possuíam até oito anos de escolaridade; 


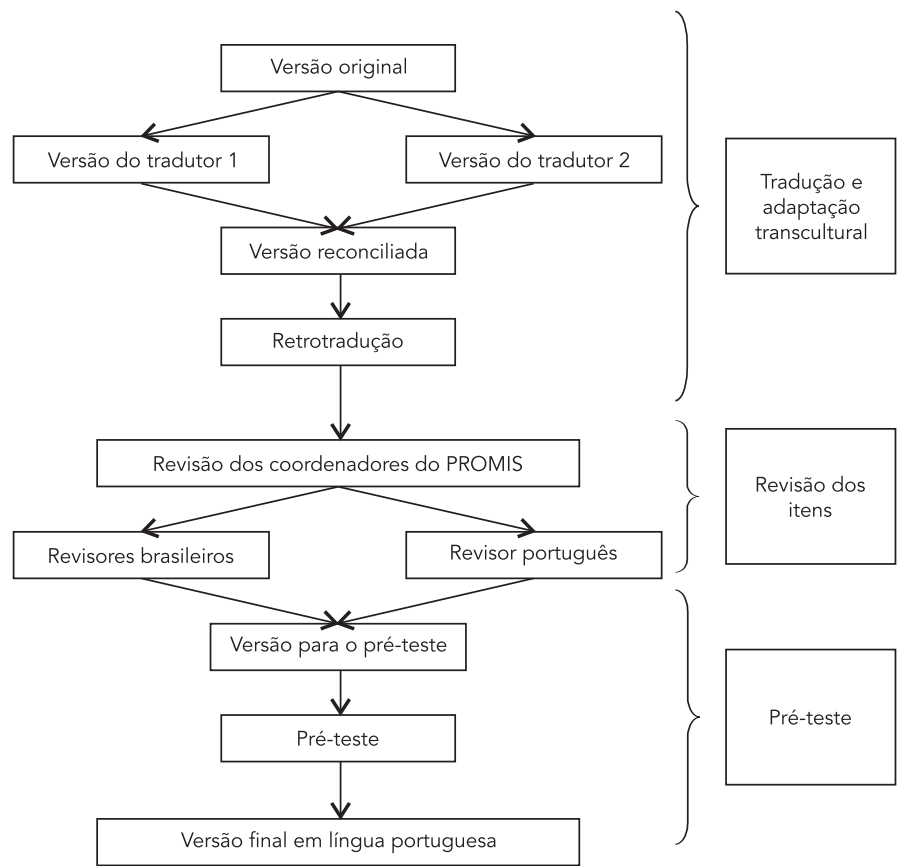

55\%, até 11 anos e 40\%, no mínimo 13 anos de escolaridade;

h) Definição final do item traduzido: os itens foram enviados aos administradores do PROMIS para análise e definição da versão final.

\section{Resultados}

Ocorreram divergências nas traduções de alguns itens. Inicialmente, os administradores do PROMIS e o revisor de Portugal optaram pela exclusão do pronome pessoal de tratamento "você" nos itens, o que gerou discordância com os revisores brasileiros. Ao final, houve um consenso geral por sua manutenção.

No item 3 "How often did you have to push yourself to get things done because of your fatigue?", houve divergência na tradução de "to push yourself" que passou de "impulsionar a si mesmo" e "se pressionar" para "se esforçar". Da mesma forma, o termo "to get things done" passou de "para fazer as coisas" para "para conseguir fazer as coisas". O revisor brasileiro sugeriu adaptar esse termo para "terminar as coisas", o que não foi aceito pelos administradores do PROMIS, pois coincidiria com a tradução de "to do/make things”, conflitando com a tradução do item 14 "Com que frequência você teve dificuldade em terminar coisas por causa da fadiga?”. O consenso entre os revisores para a tradução de "to push yourself" e "to get things done" foi "se esforçar" e "para conseguir fazer as coisas", respectivamente.

O termo "to do errands", do item 11 "How often were you too tired to do errands?", foi traduzido e reconciliado como "fazer seus afazeres". Foi sugerido pelo revisor brasileiro que se utilizasse como tradução para o termo "errands", "tarefas fora de casa” que foi aceito pelos outros revisores. Já o termo "too tired" foi traduzido como "tão cansado(a)”, “demasiadamente cansado(a)” e reconciliado como "cansado(a) demais". A tradução "cansado(a) demais" foi aceita como tradução de "too tired".

O item 25 "How hard was it for you to carry on a conversation because of your fatigue?", inicialmente foi traduzido como "Qual foi a dificuldade para você puxar conversar com as pessoas devido a sua fadiga?" e "Quão difícil era para você continuar uma conversa por causa de sua fadiga?" e, ao final, como "Quão difícil foi para você continuar uma conversa por causa de sua fadiga?". 
A expressão "quão difícil" foi revisada. Os administradores do PROMIS sugeriram um ajuste para "até que ponto você teve dificuldade" que foi aceito pelos revisores do Brasil e de Portugal. Ainda nesse item, a expressão reconciliada como "continuar uma conversa" foi revisada e adaptada para "manter uma conversa" e finalizou como "Até que ponto você teve dificuldade em manter uma conversa...".

No pré-teste, quatro itens sofreram adaptações culturais devido à dificuldade de entendimento por parte dos respondentes, mantendo suas equivalências conceitual, cultural e semântica dos itens. As adaptações transculturais desses itens tiveram aprovação do administrador do PROMIS e do revisor de Portugal. No item 53, $60 \%$ dos respondentes tiveram dificuldades em entender o termo "exaurido(a)/esvaído(a)", assim como no item 58 em que outros $60 \%$ apresentaram dificuldades no entendimento do item. Esses itens sofreram adaptações transculturais e semânticas. Nos itens 54 e 74, 100\% dos respondentes não responderam de acordo com a definição dos itens para o termo abatido(a).

O banco de itens Fadiga do PROMIS traduzido e adaptado para a língua portuguesa está apresentado na Figura 2.

\section{Discussão}

Nesse estudo, durante o processo de tradução e adaptação transcultural e revisão dos itens, a busca pelas equivalências conceitual, cultural e semântica gerou discussão somente em três dos 82 itens que necessitaram ser adaptados transculturalmente para contemplar termos ou expressões que são mais usuais para população de língua portuguesa.

De acordo com os revisores de Portugal e do PROMIS, o uso do pronome pessoal de tratamento "você" nas frases não é usual em Portugal e por isso poderia ser suprimido para garantir a universalidade dos itens. $\mathrm{O}$ revisor brasileiro se posicionou contrariamente, alegando que os itens poderiam gerar interpretações dúbias com as conjugações dos verbos, uma vez que poderiam ser confundidos com os pronomes pessoais "ele, ela ou o próprio pronome de tratamento você" 7 . Por fim, ficou definida a manutenção desse pronome nos itens.

Após o pré-teste, os termos abatido(a) e exaurido(a)/esvaído(a) necessitaram de ajustes devido às dificuldades de entendimento dos participantes. Nas adaptações, optou-se por termos mais usuais como "lento(a) e esgotado(a) física e emocionalmente", mantendo, assim, a equivalência conceitual, cultural e semântica, assim como sua clareza, compreensão e aceitabilidade. A dificuldade de compreensão de algumas palavras durante a fase de pré-teste não pôde ser atribuída ao nível de escolaridade dos respondentes, mas sim devido à baixa frequência do uso desses termos no cotidiano da população brasileira.

O banco de itens Fadiga do PROMIS está em fase de validação para a população brasileira e cada item está sendo testado quanto à sua validade e, pela análise de Rasch para comprovação da unidimensionalidade, independência local e funcionamento diferencial dos itens (DIF), a fim de confirmar o conteúdo semântico, linguístico, conceitual e cultural dos itens. A consideração da possibilidade da universalização da tradução desse banco de itens para todos os países que compõem a Comunidade dos Países de Língua Portuguesa, conforme preconizado pelos administradores do PROMIS poderá ser resolvida no processo de adaptação transcultural do banco de itens Fadiga do PROMIS para cada um desses países.

O objetivo proposto foi alcançado de forma satisfatória com a manutenção das equivalências conceitual, cultural e semântica dos itens. 
Tradução final do banco de itens do Patient-Reported-Outcome Measurement Information System - Fatigue (PROMIS - Fadiga).

\begin{tabular}{|c|c|c|c|c|c|c|}
\hline \multicolumn{7}{|c|}{$\begin{array}{l}\text { PROMIS - Fadiga: versão em língua portuguesa } \\
\text { Por favor, responda a cada item marcando apenas uma resposta por item. } \\
\text { Nos últimos } 7 \text { dias... }\end{array}$} \\
\hline 01 & $\begin{array}{c}\text { Até que ponto você teve que se esforçar para conseguir } \\
\text { fazer as coisas por causa da fadiga? }\end{array}$ & Nem um pouco & Um pouco & Mais ou menos & Muito & Muitíssimo \\
\hline 02 & Até que ponto o seu raciocínio ficou mais lento por causa da fadiga? & Nem um pouco & Um pouco & Mais ou menos & Muito & Muitíssimo \\
\hline 03 & $\begin{array}{c}\text { Com que frequência você teve que se esforçar } \\
\text { para conseguir fazer as coisas por causa da fadiga? }\end{array}$ & Nunca & Raramente & Algumas vezes & Muitas vezes & Sempre \\
\hline 04 & Com que frequência a fadiga interferiu nas suas atividades sociais? & Nunca & Raramente & Algumas vezes & Muitas vezes & Sempre \\
\hline 05 & $\begin{array}{l}\text { Com que frequência você ficou menos eficiente no trabalho por } \\
\text { causa da fadiga (incluindo o trabalho em casa)? }\end{array}$ & Nunca & Raramente & Algumas vezes & Muitas vezes & Sempre \\
\hline 06 & $\begin{array}{l}\text { Com que frequência o seu raciocínio ficou mais lento } \\
\text { por causa da fadiga? }\end{array}$ & Nunca & Raramente & Algumas vezes & Muitas vezes & Sempre \\
\hline 07 & Com que frequência você ficou cansado(a) demais para ver televisão? & Nunca & Raramente & Algumas vezes & Muitas vezes & Sempre \\
\hline 08 & $\begin{array}{c}\text { Com que frequência a fadiga fez com que você tivesse dificuldade } \\
\text { em planejar (planear) atividades com antecedência? }\end{array}$ & Nunca & Raramente & Algumas vezes & Muitas vezes & Sempre \\
\hline 09 & $\begin{array}{c}\text { Com que frequência você teve dificuldade em começar } \\
\text { algo novo por causa da fadiga? }\end{array}$ & Nunca & Raramente & Algumas vezes & Muitas vezes & Sempre \\
\hline 10 & $\begin{array}{l}\text { Com que frequência a fadiga fez com que } \\
\text { você ficasse mais esquecido(a)? }\end{array}$ & Nunca & Raramente & Algumas vezes & Muitas vezes & Sempre \\
\hline 11 & $\begin{array}{c}\text { Com que frequência você ficou cansado(a) demais } \\
\text { para fazer tarefas fora de casa? }\end{array}$ & Nunca & Raramente & Algumas vezes & Muitas vezes & Sempre \\
\hline 12 & $\begin{array}{l}\text { Com que frequência a fadiga dificultou a organização dos seus } \\
\text { pensamentos ao fazer as coisas no trabalho } \\
\text { (incluindo o trabalho em casa)? }\end{array}$ & Nunca & Raramente & Algumas vezes & Muitas vezes & Sempre \\
\hline 13 & $\begin{array}{c}\text { Com que frequência a fadiga interferiu na sua capacidade de } \\
\text { participar em atividades de lazer? }\end{array}$ & Nunca & Raramente & Algumas vezes & Muitas vezes & Sempre \\
\hline 14 & $\begin{array}{c}\text { Com que frequência você teve dificuldade em terminar } \\
\text { coisas por causa da fadiga? }\end{array}$ & Nunca & Raramente & Algumas vezes & Muitas vezes & Sempre \\
\hline 15 & $\begin{array}{l}\text { Com que frequência teve dificuldade em tomar } \\
\text { decisões por causa da fadiga? }\end{array}$ & Nunca & Raramente & Algumas vezes & Muitas vezes & Sempre \\
\hline 16 & $\begin{array}{l}\text { Com que frequência você teve que limitar as suas } \\
\text { atividades sociais por causa da fadiga? }\end{array}$ & Nunca & Raramente & Algumas vezes & Muitas vezes & Sempre \\
\hline 17 & $\begin{array}{c}\text { Com que frequência você ficou cansado(a) demais } \\
\text { para fazer tarefas domésticas? }\end{array}$ & Nunca & Raramente & Algumas vezes & Muitas vezes & Sempre \\
\hline 18 & Com que frequência você ficou menos alerta por causa da fadiga? & Nunca & Raramente & Algumas vezes & Muitas vezes & Sempre \\
\hline 19 & $\begin{array}{l}\text { Com que frequência você esteve cansado(a) demais para tomar } \\
\qquad \text { um banho de banheira ou de chuveiro? }\end{array}$ & Nunca & Raramente & Algumas vezes & Muitas vezes & Sempre \\
\hline 20 & $\begin{array}{l}\text { Com que frequência a fadiga dificultou a organização } \\
\text { dos seus pensamentos ao fazer as coisas em casa? }\end{array}$ & Nunca & Raramente & Algumas vezes & Muitas vezes & Sempre \\
\hline 21 & $\begin{array}{c}\text { Com que frequência você teve dificuldade em começar } \\
\text { coisas por causa da fadiga? }\end{array}$ & Nunca & Raramente & Algumas vezes & Muitas vezes & Sempre \\
\hline 22 & $\begin{array}{l}\text { Com que frequência foi um esforço manter } \\
\text { uma conversa por causa da fadiga? }\end{array}$ & Nunca & Raramente & Algumas vezes & Muitas vezes & Sempre \\
\hline 23 & $\begin{array}{l}\text { Com que frequência você ficou cansado(a) } \\
\text { demais para socializar com a família? }\end{array}$ & Nunca & Raramente & Algumas vezes & Muitas vezes & Sempre \\
\hline 24 & $\begin{array}{l}\text { Até que ponto você teve dificuldade em } \\
\text { começar coisas por causa da fadiga? }\end{array}$ & Nem um pouco & Um pouco & Mais ou menos & Muito & Muitíssimo \\
\hline
\end{tabular}


Figura 1 (continuação)

\begin{tabular}{|c|c|c|c|c|c|c|}
\hline \multicolumn{7}{|c|}{$\begin{array}{c}\text { PROMIS - Fadiga: versão em língua portuguesa } \\
\text { Por favor, responda a cada item marcando apenas uma resposta por item. } \\
\text { Nos últimos } 7 \text { dias... }\end{array}$} \\
\hline 25 & $\begin{array}{l}\text { Até que ponto você teve dificuldade em } \\
\text { manter uma conversa por causa da fadiga? }\end{array}$ & Nem um pouco & Um pouco & Mais ou menos & Muito & Muitíssimo \\
\hline 26 & $\begin{array}{l}\text { Com que frequência você ficou cansado(a) } \\
\text { demais para sair de casa? }\end{array}$ & Nunca & Raramente & Algumas vezes & Muitas vezes & Sempre \\
\hline 27 & $\begin{array}{l}\text { Com que frequência você ficou cansado(a) } \\
\text { demais para pensar com clareza? }\end{array}$ & Nunca & Raramente & Algumas vezes & Muitas vezes & Sempre \\
\hline 28 & $\begin{array}{l}\text { Com que frequência a fadiga o/a limitou } \\
\text { no trabalho (incluindo trabalho em casa)? }\end{array}$ & Nunca & Raramente & Algumas vezes & Muitas vezes & Sempre \\
\hline 29 & $\begin{array}{l}\text { Até que ponto você teve que limitar as suas } \\
\text { atividades sociais por causa da fadiga? }\end{array}$ & Nem um pouco & Um pouco & Mais ou menos & Muito & Muitíssimo \\
\hline 30 & $\begin{array}{l}\text { Até que ponto você teve dificuldade para organizar os seus } \\
\text { pensamentos ao fazer as coisas em casa por causa da fadiga? }\end{array}$ & Nem um pouco & Um pouco & Mais ou menos & Muito & Muitíssimo \\
\hline 31 & $\begin{array}{l}\text { Até que ponto você teve dificuldade para } \\
\text { começar algo novo por causa da fadiga? }\end{array}$ & Nem um pouco & Um pouco & Mais ou menos & Muito & Muitíssimo \\
\hline 32 & $\begin{array}{l}\text { Você foi menos eficiente no trabalho } \\
\text { (incluindo trabalho em casa) por causa da fadiga? }\end{array}$ & Nem um pouco & Um pouco & Mais ou menos & Muito & Muitíssimo \\
\hline 33 & $\begin{array}{l}\text { Até que ponto você teve dificuldade } \\
\text { em tomar decisões por causa da fadiga? }\end{array}$ & Nem um pouco & Um pouco & Mais ou menos & Muito & Muitíssimo \\
\hline 34 & $\begin{array}{l}\text { Com que frequência você teve energia } \\
\text { suficiente para se exercitar com vigor? }\end{array}$ & Nunca & Raramente & Algumas vezes & Muitas vezes & Sempre \\
\hline 35 & $\begin{array}{l}\text { Com que frequência você foi menos } \\
\text { eficiente em casa por causa da fadiga? }\end{array}$ & Nunca & Raramente & Algumas vezes & Muitas vezes & Sempre \\
\hline 36 & $\begin{array}{l}\text { Até que ponto a fadiga dificultou a organização dos seus } \\
\text { pensamentos ao fazer as coisas no trabalho } \\
\text { (incluindo trabalho em casa)? }\end{array}$ & Nem um pouco & Um pouco & Mais ou menos & Muito & Muitíssimo \\
\hline 37 & Até que ponto a fadiga fez com que você ficasse mais esquecido(a)? & Nem um pouco & Um pouco & Mais ou menos & Muito & Muitíssimo \\
\hline 38 & $\begin{array}{l}\text { Até que ponto a fadiga interferiu na sua capacidade } \\
\text { de participar de atividades de lazer? }\end{array}$ & Nem um pouco & Um pouco & Mais ou menos & Muito & Muitíssimo \\
\hline 39 & $\begin{array}{l}\text { Até que ponto você teve que se esforçar para se levantar da cama e } \\
\qquad \text { fazer as coisas por causa da fadiga? }\end{array}$ & Nem um pouco & Um pouco & Mais ou menos & Muito & Muitíssimo \\
\hline 40 & Até que ponto a fadiga interferiu nas suas atividades sociais? & Nem um pouco & Um pouco & Mais ou menos & Muito & Muitíssimo \\
\hline 41 & Até que ponto a fadiga interferiu no funcionamento do seu corpo? & Nem um pouco & Um pouco & Mais ou menos & Muito & Muitíssimo \\
\hline 42 & A fadiga fez com que ficasse menos eficiente em casa? & Nem um pouco & Um pouco & Mais ou menos & Muito & Muitíssimo \\
\hline 43 & $\begin{array}{l}\text { Até que ponto você teve dificuldade em } \\
\text { terminar coisas por causa da fadiga? }\end{array}$ & Nem um pouco & Um pouco & Mais ou menos & Muito & Muitíssimo \\
\hline 44 & Até que ponto a fadiga fez com que você ficasse menos alerta? & Nem um pouco & Um pouco & Mais ou menos & Muito & Muitíssimo \\
\hline 45 & $\begin{array}{c}\text { Com que frequência você ficou cansado(a) demais } \\
\text { para fazer uma caminhada curta? }\end{array}$ & Nunca & Raramente & Algumas vezes & Muitas vezes & Sempre \\
\hline 46 & $\begin{array}{c}\text { Com que frequência você teve que se esforçar para se levantar e } \\
\text { fazer as coisas por causa da fadiga? }\end{array}$ & Nunca & Raramente & Algumas vezes & Muitas vezes & Sempre \\
\hline 47 & $\begin{array}{c}\text { Com que frequência você esteve cansado } \\
\text { demais para socializar com amigos? }\end{array}$ & Nunca & Raramente & Algumas vezes & Muitas vezes & Sempre \\
\hline 48 & Com que frequência você se sentiu desgastado(a)? & Nunca & Raramente & Algumas vezes & Muitas vezes & Sempre \\
\hline 49 & Com que frequência você sentiu exaustão extrema? & Nunca & Raramente & Algumas vezes & Muitas vezes & Sempre \\
\hline 50 & $\begin{array}{l}\text { Com que frequência você se sentiu cansado(a) } \\
\text { mesmo não tendo feito nada? }\end{array}$ & Nunca & Raramente & Algumas vezes & Muitas vezes & Sempre \\
\hline 51 & $\begin{array}{l}\text { Com que frequência você sentiu que a } \\
\text { fadiga estava fora de controle? }\end{array}$ & Nunca & Raramente & Algumas vezes & Muitas vezes & Sempre \\
\hline
\end{tabular}

(continua) 


\begin{tabular}{|c|c|c|c|c|c|c|}
\hline \multicolumn{7}{|c|}{$\begin{array}{l}\text { PROMIS - Fadiga: versão em língua portuguesa } \\
\text { esponda a cada item marcando apenas uma resposta por item. } \\
\text { Nos últimos } 7 \text { dias... }\end{array}$} \\
\hline 52 & $\begin{array}{l}\text { Até que ponto você se sentiu cansado(a) } \\
\text { mesmo não tendo feito nada? }\end{array}$ & Nem um pouco & Um pouco & Mais ou menos & Muito & Muitíssimo \\
\hline 53 & $\begin{array}{l}\text { Em média, até que ponto você ficou física e } \\
\text { emocionalmente esgotado(a)? }\end{array}$ & Nem um pouco & Um pouco & Mais ou menos & Muito & Muitíssimo \\
\hline 54 & Com que frequência você se sentiu lento(a)? & Nunca & Raramente & Algumas vezes & Muitas vezes & Sempre \\
\hline 55 & Com que frequência você ficou sem energia? & Nunca & Raramente & Algumas vezes & Muitas vezes & Sempre \\
\hline 56 & Com que frequência você ficou fisicamente esgotado(a)? & Nunca & Raramente & Algumas vezes & Muitas vezes & Sempre \\
\hline 57 & Com que frequência você se sentiu cansado(a)? & Nunca & Raramente & Algumas vezes & Muitas vezes & Sempre \\
\hline 58 & $\begin{array}{l}\text { Até que ponto você ficou fatigado(a) quando } \\
\text { a fadiga estava no seu pior? }\end{array}$ & Nem um pouco & Um pouco & Mais ou menos & Muito & Muitíssimo \\
\hline 59 & $\begin{array}{l}\text { Com que frequência você se sentiu incomodado(a) } \\
\text { por causa da fadiga? }\end{array}$ & Nunca & Raramente & Algumas vezes & Muitas vezes & Sempre \\
\hline 60 & $\begin{array}{c}\text { Com que frequência você teve energia suficiente } \\
\text { para apreciar as atividades de lazer? }\end{array}$ & Nunca & Raramente & Algumas vezes & Muitas vezes & Sempre \\
\hline 61 & $\begin{array}{l}\text { Com que frequência você ficou cansado(a) } \\
\text { demais para aproveitar a vida? }\end{array}$ & Nunca & Raramente & Algumas vezes & Muitas vezes & Sempre \\
\hline 62 & $\begin{array}{l}\text { Com que frequência você ficou cansado(a) } \\
\text { demais para se sentir feliz? }\end{array}$ & Nunca & Raramente & Algumas vezes & Muitas vezes & Sempre \\
\hline 63 & Com que frequência você se sentiu totalmente esgotado(a)? & Nunca & Raramente & Algumas vezes & Muitas vezes & Sempre \\
\hline 64 & Com que frequência você ficou cheio(a) de energia? & Nunca & Raramente & Algumas vezes & Muitas vezes & Sempre \\
\hline 65 & Em média, até que ponto você se sentiu cansado(a)? & Nem um pouco & Um pouco & Mais ou menos & Muito & Muitíssimo \\
\hline 66 & Em média, até que ponto você se sentiu incomodado(a) pela fadiga? & Nem um pouco & Um pouco & Mais ou menos & Muito & Muitíssimo \\
\hline 67 & Em média, até que ponto você ficou exausto(a)? & Nem um pouco & Um pouco & Mais ou menos & Muito & Muitíssimo \\
\hline 68 & $\begin{array}{l}\text { Até que ponto você ficou fatigado(a) no dia } \\
\text { em que se sentiu mais fatigado(a)? }\end{array}$ & Nem um pouco & Um pouco & Mais ou menos & Muito & Muitíssimo \\
\hline 69 & Em média, até que ponto você se sentiu fatigado(a)? & Nem um pouco & Um pouco & Mais ou menos & Muito & Muitíssimo \\
\hline 70 & Em média, até que ponto você se sentiu desgastado(a)? & Nem um pouco & Um pouco & Mais ou menos & Muito & Muitíssimo \\
\hline 71 & Em média, quanta energia mental você teve? & Nem um pouco & Um pouco & Mais ou menos & Muito & Muitíssimo \\
\hline 72 & Em média, até que ponto você ficou fisicamente esgotado(a)? & Nem um pouco & Um pouco & Mais ou menos & Muito & Muitíssimo \\
\hline 73 & Em média, até que ponto você ficou cheio(a) de energia? & Nem um pouco & Um pouco & Mais ou menos & Muito & Muitíssimo \\
\hline 74 & Em média, até que ponto você se sentiu lento(a)? & Nem um pouco & Um pouco & Mais ou menos & Muito & Muitíssimo \\
\hline 75 & Em quantos dias a fadiga foi pior pela manhã? & Nenhum & 1 dia & 2-3 dias & 4-5 dias & $6-7$ dias \\
\hline 76 & Com que frequência você percebeu que se cansava facilmente? & Nunca & Raramente & Algumas vezes & Muitas vezes & Sempre \\
\hline 77 & Com que frequência você pensou na fadiga? & Nunca & Raramente & Algumas vezes & Muitas vezes & Sempre \\
\hline 78 & Quanta fadiga você sentiu no dia em que ficou menos fatigado(a)? & Nem um pouco & Um pouco & Mais ou menos & Muito & Muitíssimo \\
\hline 79 & $\begin{array}{l}\text { Em média, com que facilidade você percebeu que estava } \\
\qquad \text { ficando cansado(a)? }\end{array}$ & Nem um pouco & Um pouco & Mais ou menos & Muito & Muitíssimo \\
\hline 80 & Até que ponto você ficou arrasado(a)/prostrado(a)? & Nem um pouco & Um pouco & Mais ou menos & Muito & Muitíssimo \\
\hline 81 & Com que frequência você teve energia física? & Nunca & Raramente & Algumas vezes & Muitas vezes & Sempre \\
\hline 82 & Qual foi o nível da sua fadiga na maioria dos dias? & Nenhum & Leve & Moderado & Grave & Muito grave \\
\hline
\end{tabular}




\section{Resumen}

El banco de ítems del dominio fatiga forma parte de un sistema estadounidense, desarrollado para la evaluación de los resultados reportados por los pacientes denominados Patient-Reported-Outcomes Measurement Information System (PROMIS). Este estudio tuvo como objetivo traducir y adaptar interculturalmente el banco de items para que fuera sometido a la perspectiva brasileña, al tratarse de una prometedora nueva evaluación de la calidad de vida, relacionada con la salud. Los elementos en el banco se transforman utilizando un estricto protocolo de traducción y re-traducción. Sobre la versión traducida se realizaron pre-pruebas en 20 brasileños que respondieron a una breve entrevista cognitiva y retrospectiva, con el fin de probar la equivalencia conceptual, cultural y semántica de los ítems. En el proceso de traducción y re-traducción sólo tres de los 82 items tuvieron que ser rescritos. En la pre-prueba se mostró que sólo cuatro elementos son necesarios volver a escribirlos, pero sin cambio conceptual y semántico. Los resultados muestran que esta versión traducida es conceptual, cultural y semánticamente equivalente a la versión original.

Fatigue; Calidad de Vida; Traducción

\section{Colaboradores}

F. S. M. Alves, R. M. C. Pinto, T. M. S. Mendonça e C. H. M. Silva contribuíram substancialmente no projeto e delineamento, levantamento de dados, análise e interpretação, elaboração do manuscrito e sua revisão crítica e aprovação final da versão a ser aplicada.

\section{Agradecimentos}

À FAPEMIG pelo financiamento disponibilizado para a compra desse banco de itens. Ao CNPq pela bolsa de iniciação científica disponibilizada para a realização da tradução e adaptação transcultural desse banco de itens.

\section{Referências}

1. Fries JF, Bruce B, Cella D. The promise of PROMIS: using item response theory to improve assessment of patient-reported outcomes. Clin Exp Rheumatol 2005; 23(5 Suppl 39):S53-7.

2. Cell D, Gershon R, Lai J-S, Choi S. The future of outcomes measurement: item banking, tailored short-forms, and computerized adaptive assessment. Qual Life Res 2007; 16:133-41.

3. Mota DDCF, Cruz DALM, Pimenta CAM. Fadiga: uma análise do conceito. Acta Paul Enferm 2005; 18:285-93.

4. Eremenco SL, Cella D, Arnold BJ. A comprehensive method for the translation and cross-cultural validation of health status questionnaires. Eval Health Prof 2005; 28:212-32.
5. Acquadro C, Conway K, Hareendran A, Aaronson N. Literature review of methods to translate health-related quality of life questionnaires for use in multinational clinical trials. Value Health 2008; 11:509-21.

6. Hak T, Veer KVD, Jansen H. The Three-Step Test-Interview (TSTI): an observation-based method for pretesting self-completion questionnaires. Surv Res Methods 2008; 2:143-50.

7. Cunha C, Cintra L. Nova gramática do português contemporâneo. Rio de Janeiro: Lexikon; 2007.

Recebido em 23/Mai/2013

Versão final reapresentada em 28/Jan/2014

Aprovado em 10/Fev/2014 